\title{
Introducing Banu Sahra Bridge, a First and Valuable Pace to Restore It
}

\author{
Maral Fayazi, ", Dariush Heydari Bani ${ }^{1,2}$, Hamed Iman Talab ${ }^{1,3}$ \\ ${ }^{1}$ Conservation Faculty of Arts and Architecture, Azad University - Yazd Branch, Yazd, Iran \\ ${ }^{2}$ Conservation Faculty, Isfahan University of Art and Architecture, Isfahan, Iran \\ ${ }^{3}$ Faculty of Architecture, Azad University Qeshm Branch, Qeshm, Iran
}

Email address:

Mfayazi_art@yahoo.com (M. Fayazi),d.heydari@aui.ac.ir(D. H. Bani), Hamed.Imantalab@gmail.com (H. I. Talab)

\section{To cite this article:}

Maral Fayazi, Dariush Heydari Bani, Hamed Iman Talab. Introducing Banu Sahra Bridge, a First and Valuable Pace to Restore It. International Journal of Science, Technology and Society. Special Issue: Research and Practice in Architecture and Urban Studies in Developing Countries. Vol. 3, No. 2-1, 2015, pp. 122-131. doi: 10.11648/j.jjsts.s.2015030201.34

\begin{abstract}
Located in Chendar District, Savojbolagh county of Alborz Province in Iran, Banu Sahra bridge (Longitude: $50^{\circ}, 49^{\prime}, 17^{\prime \prime}$ - Latitude: $35^{\circ}, 56^{\prime}, 43^{\prime \prime}-$ Altitude, $1430 \mathrm{~m}$ from the sea level) is built on Kordan River near Banu Sahra Village. There are three historical bridges in Savojbolagh. Banu Sahra Bridge is the only bridge in this county which has two main spans and one minor span (which is remained). This construction which is built in the East-west direction is $5.5 \mathrm{~m}$ wide and its current height is 6.60 meters. Due to complete destruction of the bridge deck and its current status, probable length of this historical construction might be 33 meters. Main part of the bridge is constructed by bricks, rubbles, and cobblestones as well as breakwater (north south direction). Brick structure in addition to combination of cobblestone and rubble in foundation along with the break water (northern-southern) which have curves in both sides consist the main groundwork of the bridge. The type of the arch which is used in this construction is blunt Pang-O-Haft and load bearer. According to studies conducted in the last year, in order to become familiar with the structure and architecture of this historical monument, this article is part of the analysis and conclusions in this regard which will be presented. However, most of the provided information is based on the documentations of the bridge's recent year conditions.
\end{abstract}

Keywords: Savojbolagh, Bridge, Banu Sahra Village, Restoration Plan, Recovery Plan

\section{Introduction}

Iran is not a rainy land and there are a few watery deep rivers in it. Despite this, bridges have always been vital for the country due to vastness of previous empires in Iran and their need for transportation and communication ways over the rivers and watercourses. It probably can be said that the technical problems of building bridges are much more complicated than any other traditional construction, because in addition to its resistance against climatic factors such as sunlight, wind, rainfall, frost, and temperature fluctuation, it should also withstand the erosion resulted by continuous water flow, intermittent clamorous floods and trundling stones of the river. Hence, in order to build this structure, resistant materials as well as mortar of lime and Sarouj (Mortar Concrete) "Resistant to water and moisture" are used. Furthermore, due to the importance of resistance of the soil under the bridge, constructing it on a rocky substrate so that it can benefit a solid and lasting foundation was always preferred. Therefore, intensity and state of water stream are decisive factors in determining the location of the bridge. In other word, points with low velocity and intensity were considered as the best places.

\section{Background and Place of Construction}

Banu Sahra Bridge ${ }^{1}$ is located in the south of Kordan-valian road, Chendar district (1 kilometer to Kordan Village) and near to Banusahra village ${ }^{2}$, in a position that at the time of crossing $^{3}$ the Kordan River $^{4}$-in the narrowest

\footnotetext{
1 (National Register No. 11104 in 2004)

2 On Tehran-Qazvin highway, on the way to Kouhsar city, at the distance of $24 \mathrm{Km}$ (roughly) from Karaj, located in Chendar district, savojbolagh county, on the northern west side of Karaj.

3 In 1969, a concrete bridge was built on Kordan River to reconnect Kordan Village to Bau Sahra village in a new path.
} 
point- one can see it. This construction was in well status from the Gajarid era until $1974(1353 \mathrm{H})$ but crumbled into ruins from that year until the time of reaching record as a national monument in $2004(1383 \mathrm{H})$. According to experts considering dimensions of used bricks in different parts of the structure, it dates back to the Safavid era which was repaired in the Qajarid era (Figures 1-4) (Alborz Cultural Heritage Administration).

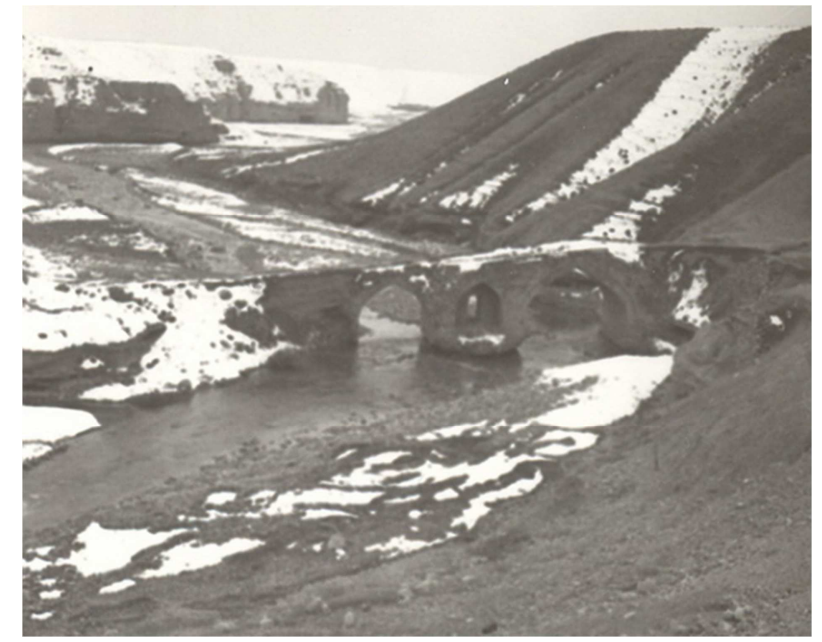

Figure 1. North facade of Banu sahra Bridge (Savojbolagh Cultural Heritage Office, 1974).
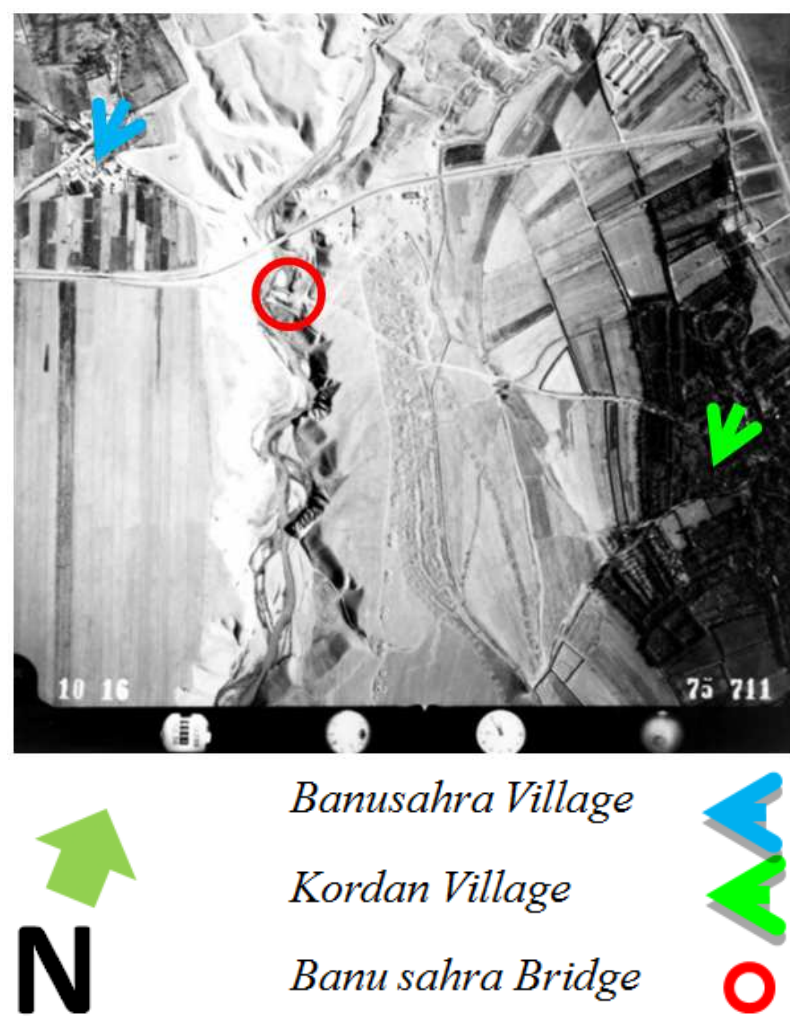

Figure 2. Aerial Photo, 1975, National Cartographic Center.

4 Kordan River emanates from Baraghand Vardeh mountains and is watery during winter and early spring. However, the river water has become very little in recent years due to the facilities such as diversion dam constructed by Alborz Province water and Waste Water Company.

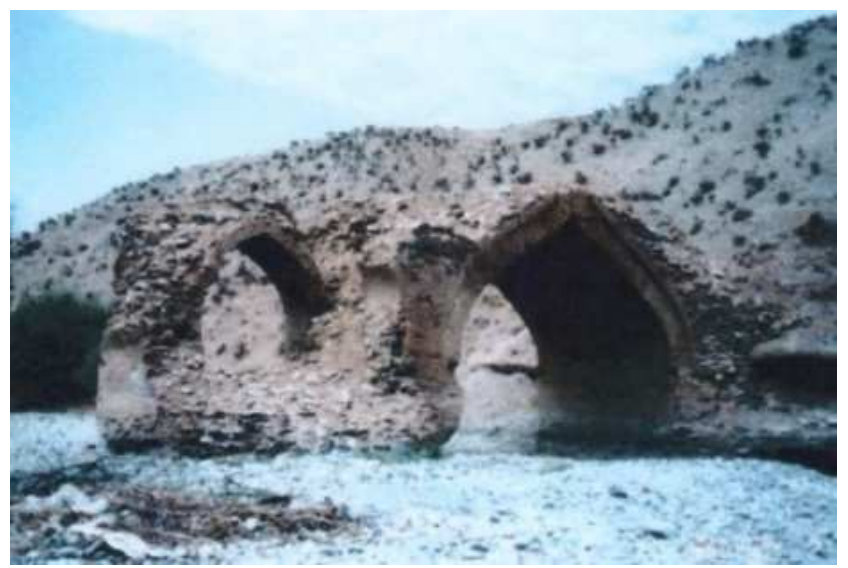

Figure 3. North facade, Cultural Heritage organization of Tehran Province, 2004

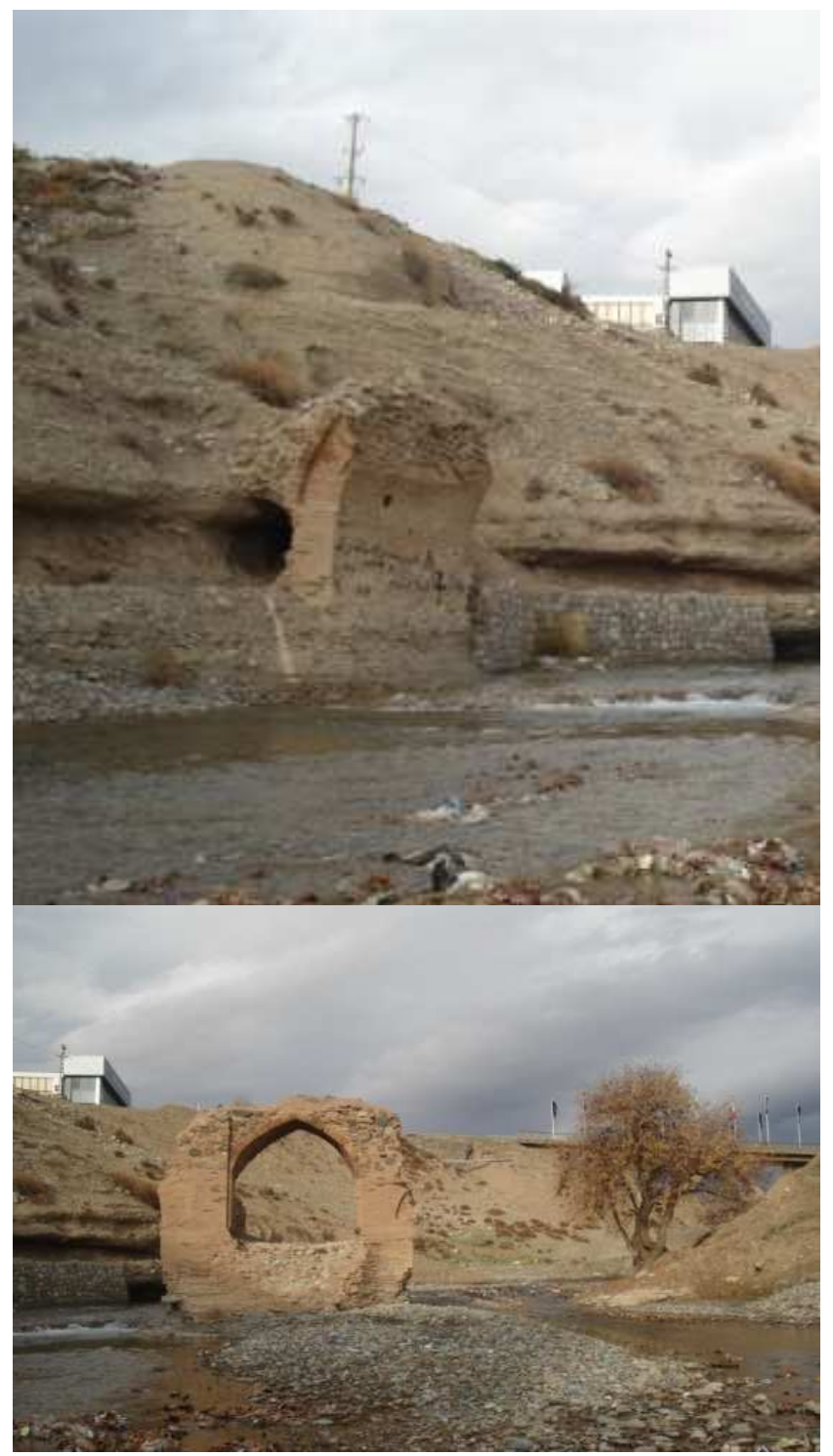

Figure 4. South facade of Banu sahra Bridge, autumn of 2013, the author.

\section{The Architecture}

At the narrowest point of Kordan seasonal river, in the 
west-east direction ${ }^{5}$ close to the river curve, Banusahra Safivid Bridge is constructed. It is only in the west side (which is remained) that the main foundation is built relying on the natural base (a rock along with a combination of sand, gravel and clay soil). On the east side, the bricklaying of the abutment was at the same level of the west side but unfortunately this part is destroyed because of lack of soil stability. Due to the use of the natural substrate, the width of the bridge is roughly 5.5 meters $^{6}$ and with a maximum height of $6.60 \mathrm{~m}$ (from the riverbed at a slope of $0.8 \%$ ) still remains. It is remarkable to note that due to the height of the natural wall of the river in the west side, it can be estimated that the original height of the bridge was 8 meters. From the structural point of view, the bridge had 2 main arches and a sub-arch in the middle of the structure. It's total length was roughly 33 meters ${ }^{7}$. The length of main arches was not equal. On the west side, from the northern façade, it was $7.90 \mathrm{~m}$, from southern façade $8 \mathrm{~m}$, and on the east side it was $5.5 \mathrm{~m}$ according to the remains of the foundation. The maximum height of the main arch is not observable now because of destructions but from the remained arch base we can say that the western and eastern arches were 6.96 and $5.96 \mathrm{~m}$ respectively. The dimensions of medial arch, from the southern façade (the intact arch) were $3.70 \mathrm{~m}$ (height) and $3.27 \mathrm{~m}$ (length). Wooden beams with a diameter of 22 to $25 \mathrm{~cm}$ are located at the height of $2.70 \mathrm{~m}$ from the riverbed; and their horizontal distance from the center of the beams is 2.3, and 2.22 (from northern side). The very limited ornaments of the bridge are recess and bricklaying $(10 \mathrm{~cm})$ with a cobblestone façade on the top of the arch. The mentioned recess is $10 \mathrm{~cm}$ in Konu and $30 \mathrm{~cm}$ in the remained base of the main arch in the west side. The dimensions of the breakwater of the northern façade has been changed due to emergency repairs which were done in the past years but it can certainly be said that in both sides they are curved shape i.e. a semicircular with the radius of $1.6810 \mathrm{~m}$ in the southern side has changed the geometrical shape of the main breakwater and has made a curve from both sides which joins the main walls.

There was a stone inscription on the highest point of the bridge which has been removed from the structure due to severe damages during passed years. Unfortunately the content of the inscription has not been recorded anywhere (Keshavarz zadeh, 2014). The different components of this bridge can be described in the following parts based on its function and structure as well as expectations from and needs about building it:

\subsection{Sentry Fortress}

At the closest horizontal distance (roughly $6 \mathrm{~m}$ ) in the eastern side, one can see the remains of a structure which probably was a sentry fortress in order to protect caravans and

\footnotetext{
5 The main axis of the construction (the bridge is built in western- eastern direction due to the northern- southern position of the river bed).

6 The width is suitable for passing a Russian jeep (according to Haj Shaban Keshavarz zadeh the last headman of Banu Sahra village.

7 The length is not accurate because of severe damages in 1975.
}

residents due to the importance of this bridge in old times and the status of Savojbolagh from economical and political point of view, as well as taking toll and taxes.

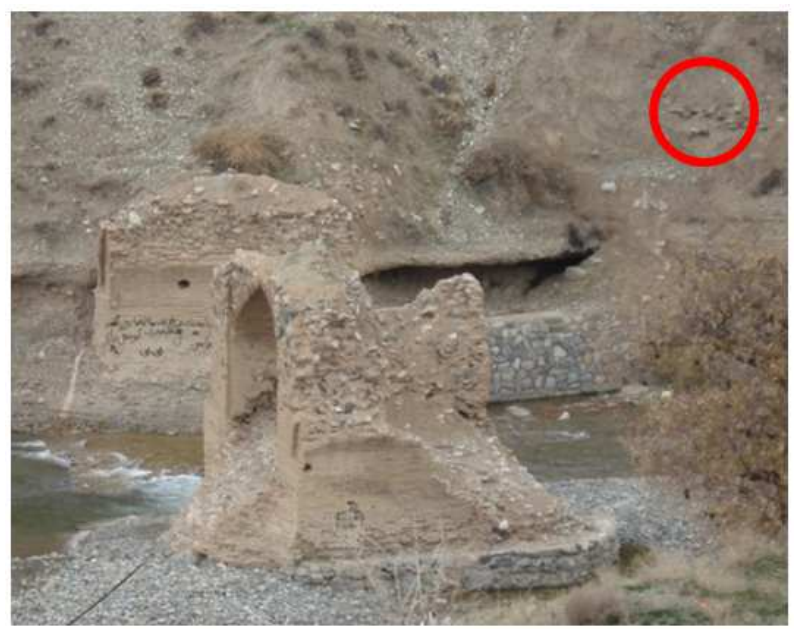

Figure 5. Eastern facade and ruins of the sentry fortress, the author, autumn of 2013.

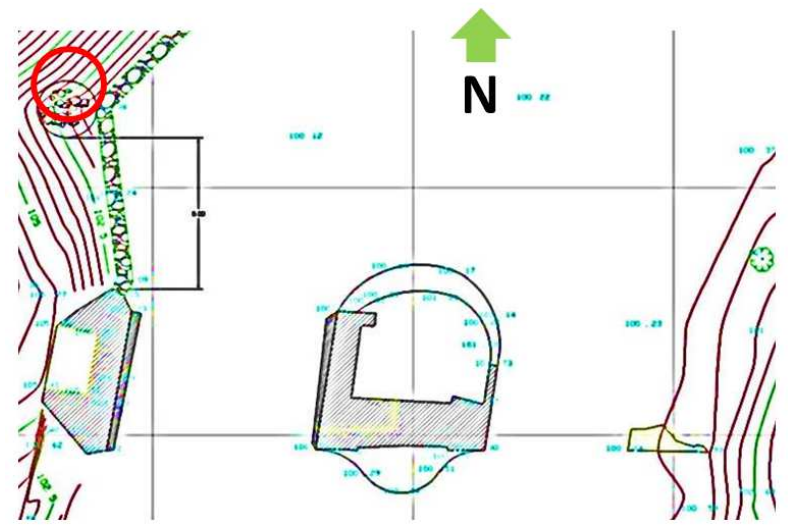

Map 1. Position of ruins of the sentry fortress on the plan, the author, autumn of 2013 .

\subsection{Break Water}

The best form of the breakwater is a foundation or a base which is curved from both sides. According to the plan, this part of the bridge has a semicircular shape in the northern side (upstream) but there is a little curve in the southern side (downstream). Based on (figure 6) the breakwater and the medial pile are located on the natural and rocky substrate of the river for further reinforcement. This solid substrate is the determinant of the length of arches. Hence, length of arches is unequal and asymmetric.

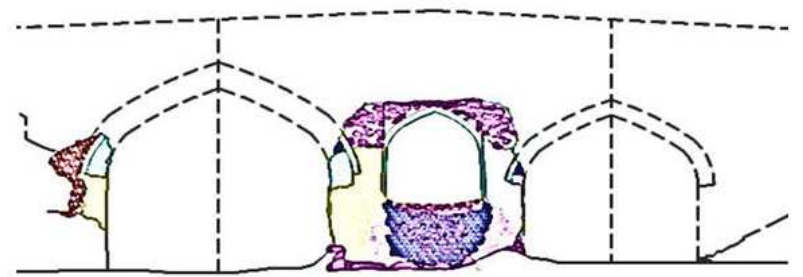

Figure 6. Southern façade. 


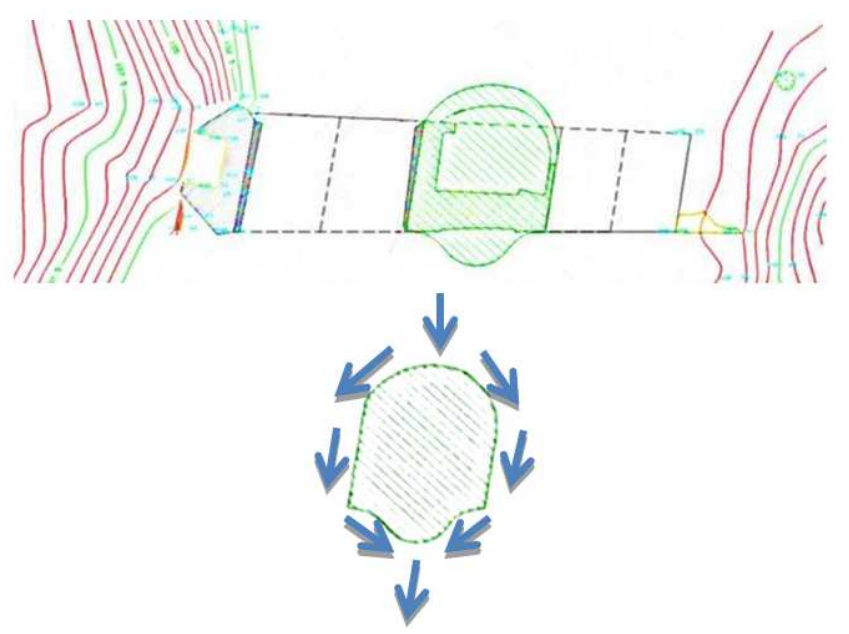

Figure 7. Geometrical shape of the breakwaters on the plan.
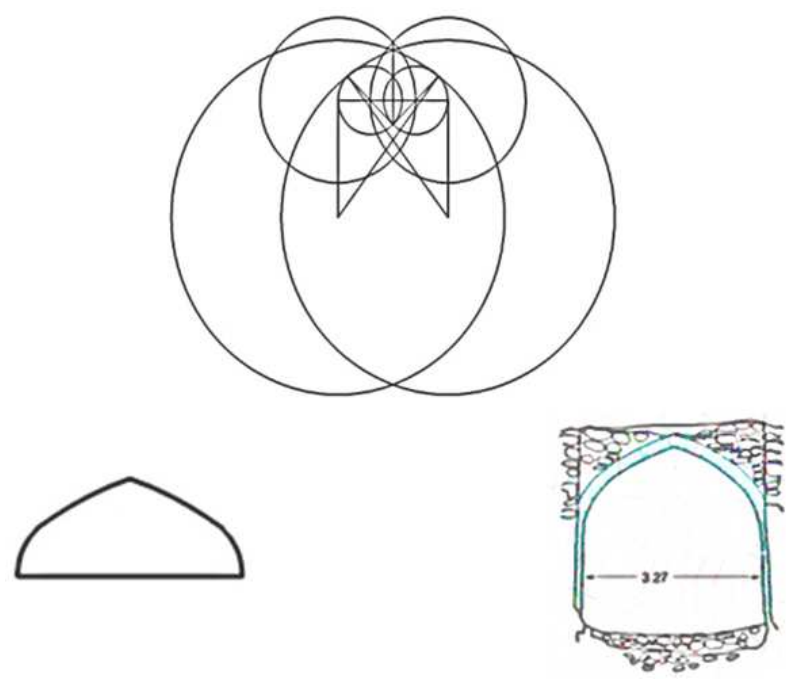

Figure 8. Tracing blunt Pang-O- Haft arch on the medial span (the author).

\subsection{Type of Arches}

Like any other architectural element, arch has its own geometric and unique shape. Among all types of arches which some are load bearing and some are not, blunt Pang-O-Haft arch is used. This is proved by considering the remained piers of the original span on the western, and the eastern side. Hence, this arch is matched with the original vaults.

\subsection{Ornaments}

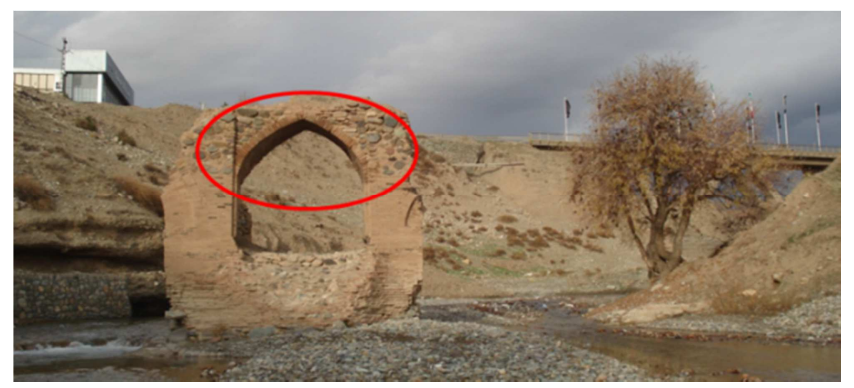

Figure 9. Stony facade (clone stone), southern side, top of medial arch, author, 2013.

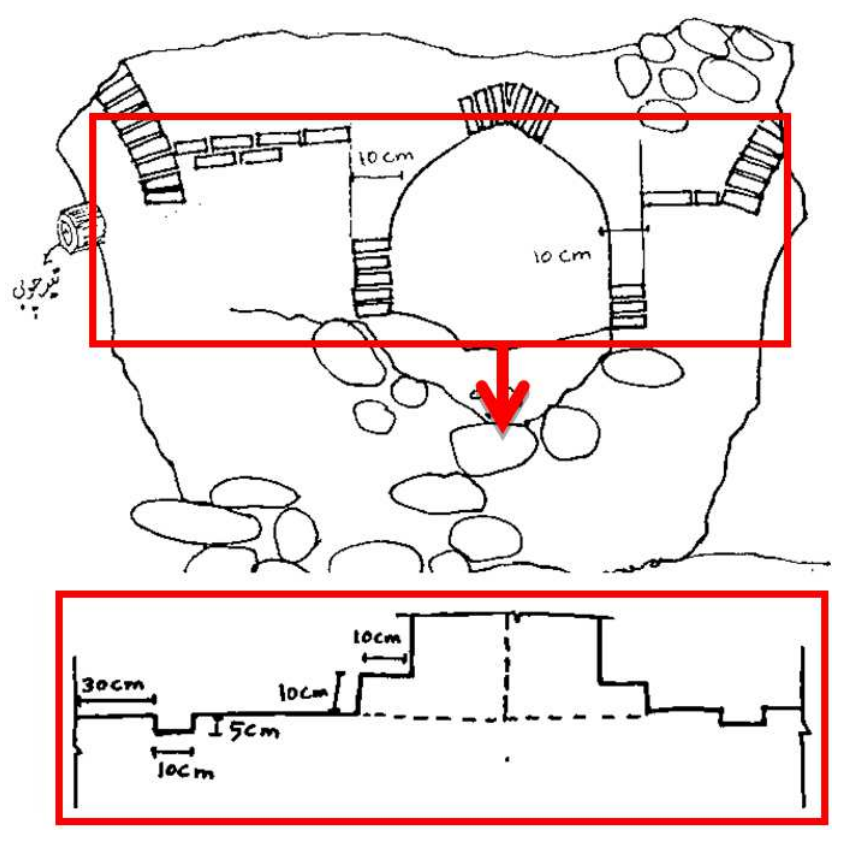

Figure 10. Author.

Because of the bricks dimensions in the pier (which is $20 \mathrm{x}$ $20 \times 4.5 \mathrm{~cm}$ ), the bridge is contributed to the Safavid era. Furthermore, since different sizes of bricks are used, it can be concluded that the bridge has been repaired in the past. The recesses and bulges are made by transposing the bricks. In order to embellish the southern facade, cobblestone is used at the top of the medial arch (Figures 9 and 10).

\section{Structure of Banu Sahra Bridge}

Many factors including river flood peak, hydraulics, hydrology of river and bridge, geology, structure materials, and using appropriate executive procedures has been considered in designing and building the bridges. In this part, some of these factors which are more observable in Banu Sahra Bridge will be discussed.

\subsection{Materials}

Banu Sahra Bridge is built by available and vernacular materials. Cobblestone which is inexpensive, resistant and lasting is used a lot in foundation, abutment, pier and in facade. Arches ${ }^{8}$ and the ornaments of exterior walls are built by the ${ }^{9}$ bricks dimensions of $24 \times 24 \times 4.5 \mathrm{~cm}$ and $20 \times 20 \times 5$. Wooden beams with the diameter of 22 to $25 \mathrm{~cm}$ are located in the height of 2.70 meters from the riverbed. The horizontal distances between wooden beams are 2.3 , and $2.22 \mathrm{~cm}$ in the widths of the arch. These beams were used as scaffold at the base of the arches and at the end of the project were cut. The outer incrustation of the framework and arches are decorated by bricks. The foundation is built by cobblestone based in order to strengthening and retrofitting against pressure of weight of arches and walls.

8 Barrel Vault

9 Some bricks with other dimensions such as $22 \times 22 \times 4.5 \mathrm{~cm}$ are also found. 


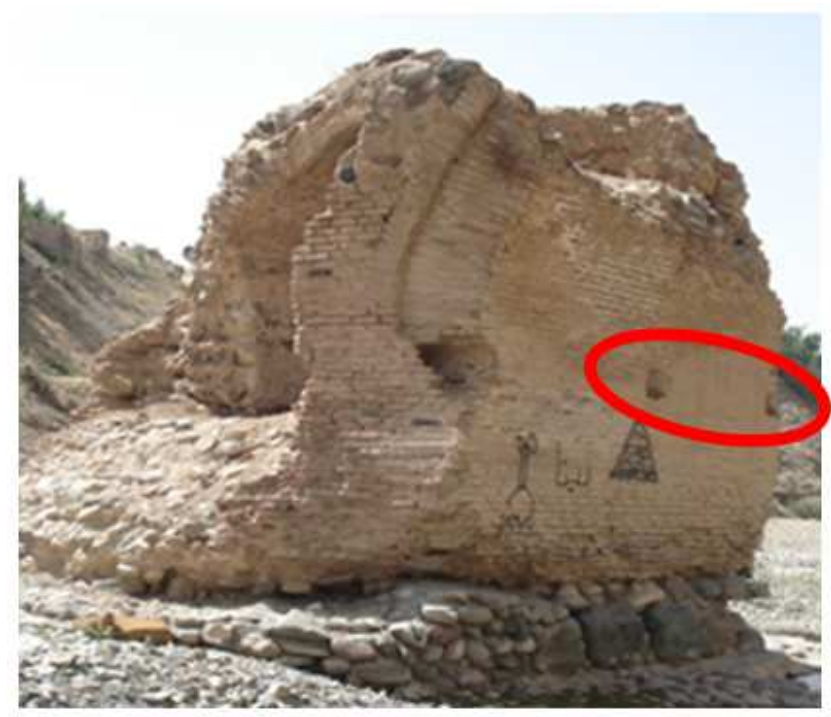

Figure 11. Wooden beams, western.

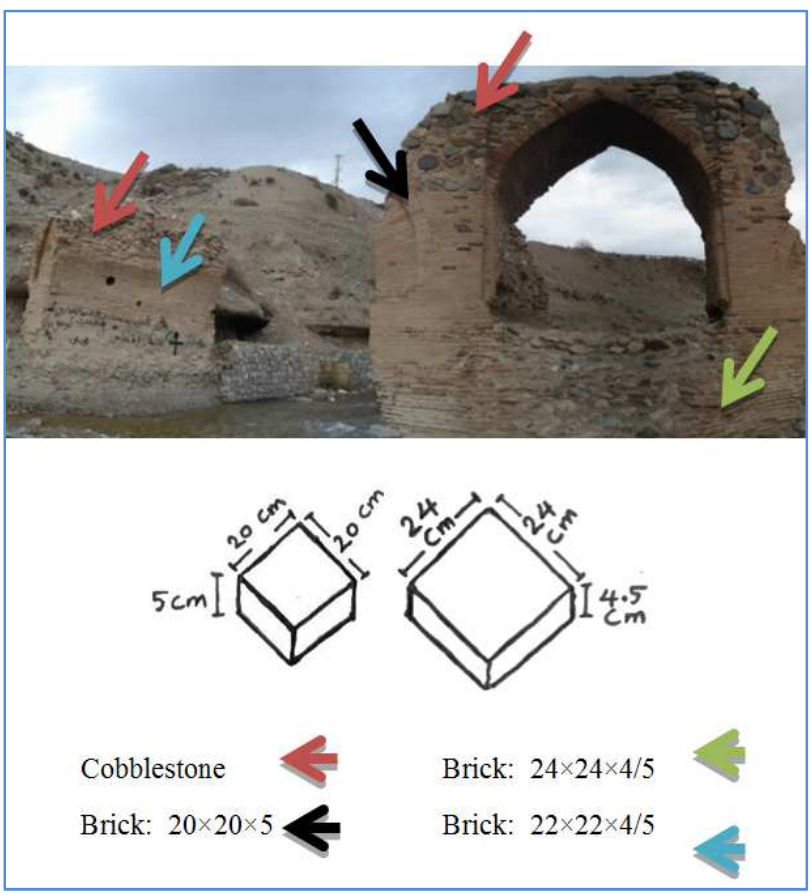

Figure 12. Position of materials.

\subsection{Mortar}

After sampling from the used mortars in different parts of the structure including the upper, lower and middle parts, and executing XRF and XRD tests, it was found that in general, Sarouj ${ }^{10}$ is used in foundation (the lowest part)and grouting in this bridge. At the highest remained point, a combination of plaster and soil is used as mortar. Furthermore, mud and plaster is seen as mortar in the piers.

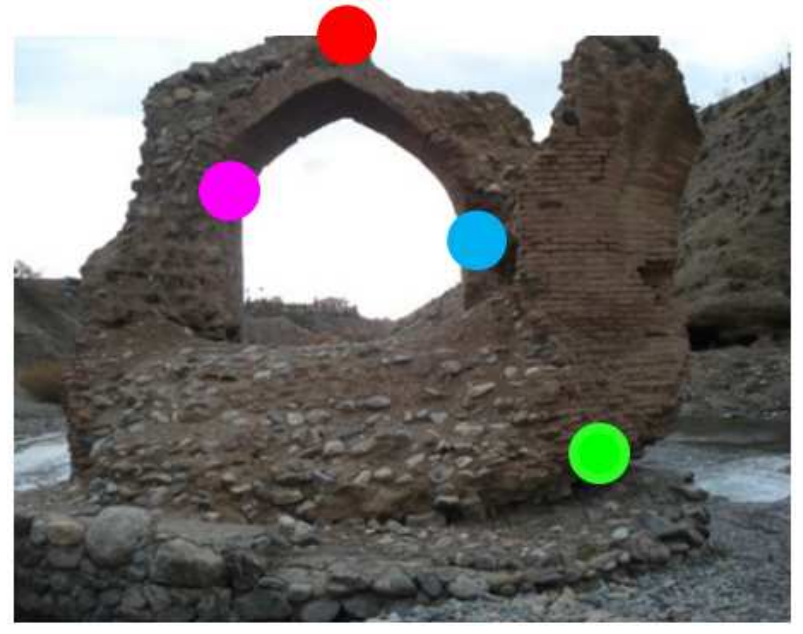

Place of sampling

The lowest point (after concrete stone laying)

\section{Mortar}

Remained highest point

Mortar of middle of the structure

Figure 13. Position of sampling in northern side, 2013.

\subsection{Filling over the Arches}

Since the pressure of water and slope of the river was high, the body of the bridge must have been heavy enough in order to be able to resist against above-mentioned pressures. Hence, the arches were made heavy by clone stones and mortar of plaster and soil.

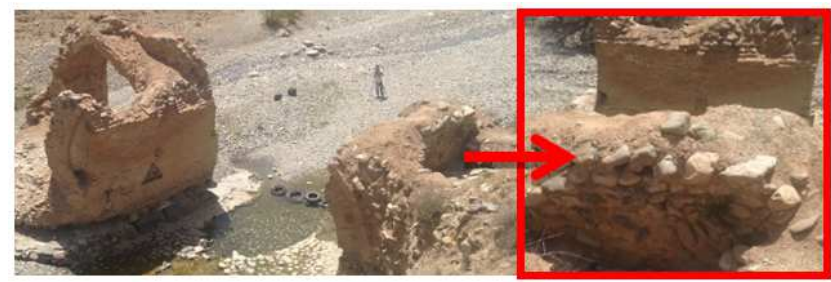

Figure 14. Summer of 2013.

\subsection{Force Transmission and Bearing}

\subsubsection{Bearing System}

In this structure, the bearing system is a combination of the pier and the arch which its shapes are as follows:

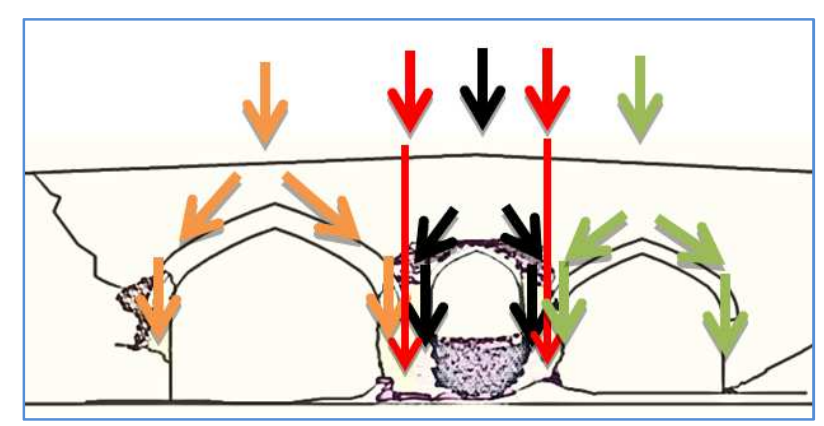

Figure 15. Force transmission in the original status. 


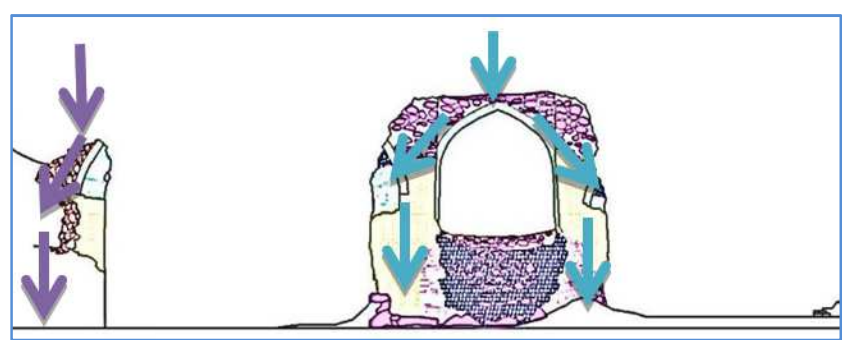

Figure 16. Force transmission at the present time.

\subsubsection{Level Difference of Spring Lines}

In the time of flatting the surface of the bridge after building the arches, it is necessary to fill the recesses of back of the arches, between arches, and on the pillars in order to minimize the pressures and prevent arch sliding. Therefore, the medial arch is constructed on the higher level in comparison with the level of the main arch. Hence, the spring lines of the media and main arches are not in a same level. Therefore, level difference is made in order to neutralize the forces of medial arch on the walls by the main arches.

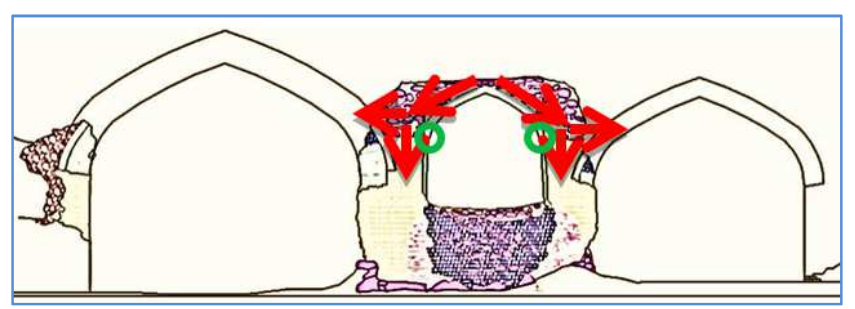

Figure 17. Higher level of the medial arch.

\subsection{The Medial Arch (Ventilator - Konu)}

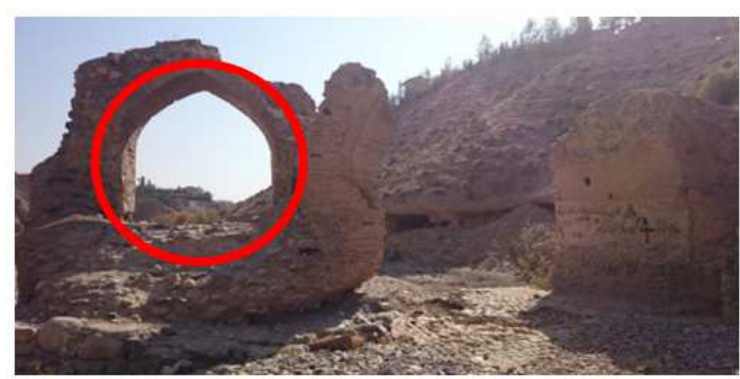

Figure 18. Medial span, Summer of 2013.

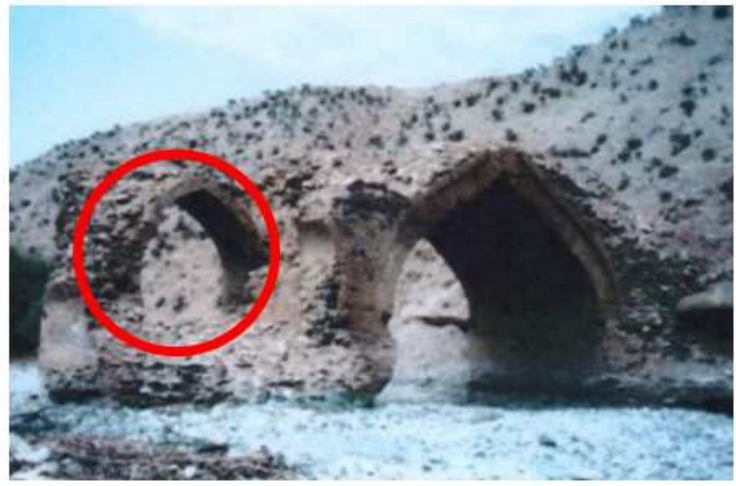

Figure 19. Northern facade of the bridge and the visible medial arch, spring of 2013 .
In most historical bridges, arches are designed to make suitable and enough space between arches and level of flood (when a maximum flood occurs). This space is called ventilator. This part of a bridge is vital for facilitating evacuation of flood and passing consignments such as tree branches and trunks (Heydari Bani,1999, P.423). So, the medial arch is the ventilator which also plays an important role in reducing the load on piers and foundation.

\subsection{Arch in Vaults}

As it was mentioned in previous pages, all arches of the bridge are blunt Pang-o Haft which is the most powerful type of arch to bear forces among all types of load bearing arches (after lancet Pang-O-Haft). This arch is fortified and constructible in bridges if only good materials are used in the right way because of low altitude, small width of the river and small span (up to 3 to $4 \mathrm{Gaz}^{11}$ equals to roughly 4 meters). But of course this is not suitable for bigger spans from resistance and strength point of view. However, blunt arches are built instead of lancet arches in this bridge, because the latter makes high slope in the deck and vault of the bridge which in turn makes traffic more difficult. The constructors have used other solutions for compensating tolerance of forces.

One of these solutions is integrating roman and barrel bricklaying (Part: 4.7.). The other solution is burdening the foundation (Part: 4.8.) and the skewback by thickening walls in order to make sure about balancing arches and neutralizing their thrust force.

\subsection{How to Build Wagon Vault in the Medial Arch: Bricklaying and Integration of Elimite (Ogive Vault) and Rhythmic Arch}

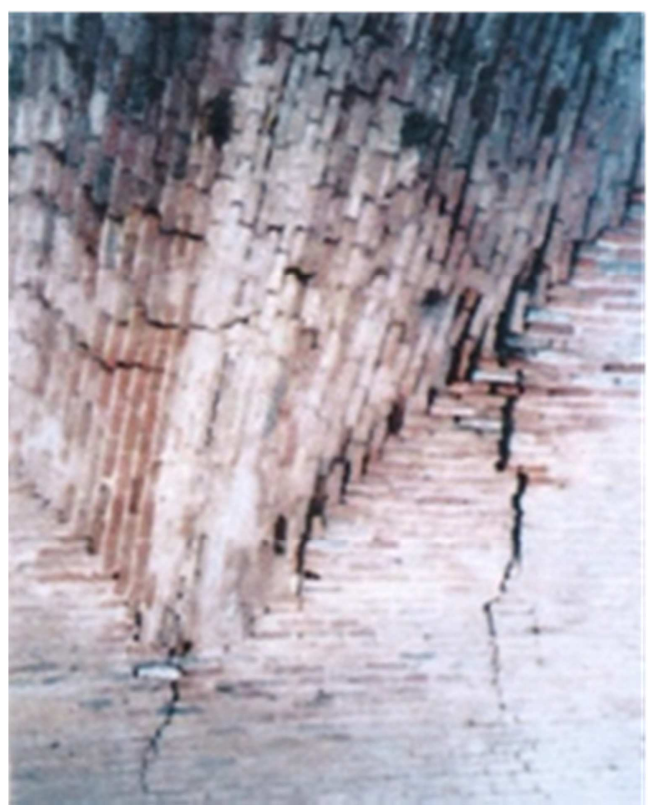

Figure 20. Western wall of medial vault (Rhythmic Arch), 2004, Tehran Province Cultural Heritage Organization.

11 A unit of Length which equals to $104 \mathrm{~cm}$ 
Elimite Arch is very strong by itself but because it must be laid on a template, it can be very hard to build it and therefore the constructers build it to the point of haunch (Shekangah) without using any template- or by using a small template. Then, above the haunch is built by using thin and small templates of vaults. Because vaults are weak, overloading leads to decomposition (So-Called: Par Par Shodan).
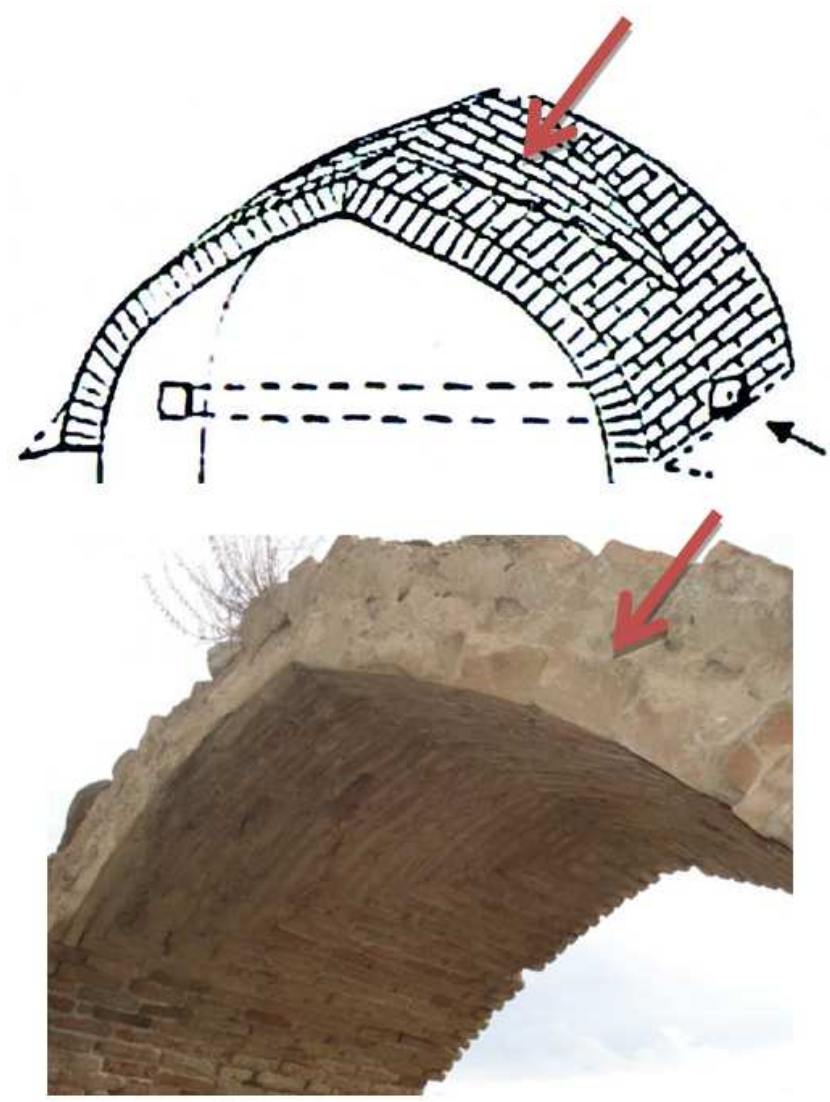

Figure 21. Remained part of the medial vault, 2012.

\subsection{Foundation}

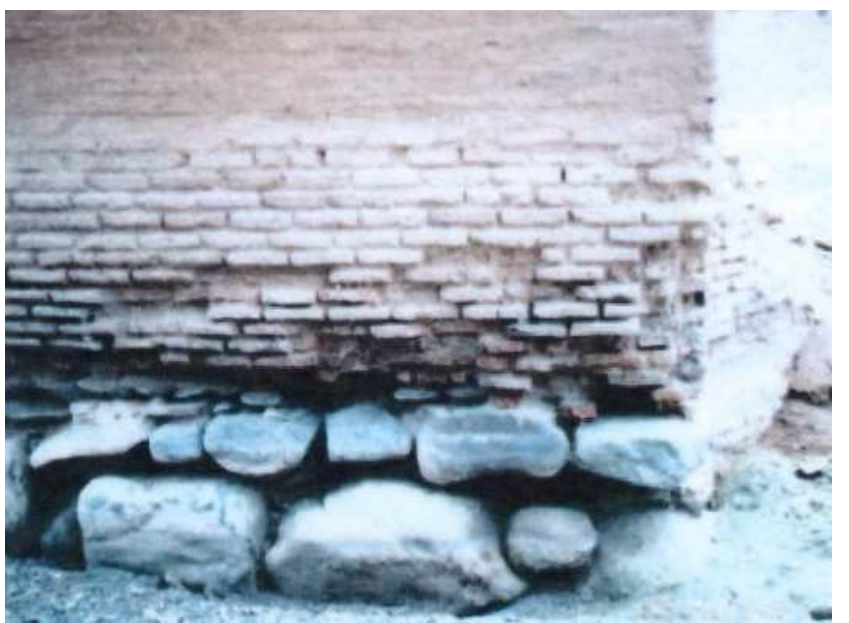

Figure 22. Foundation of the medial vault, 2004.

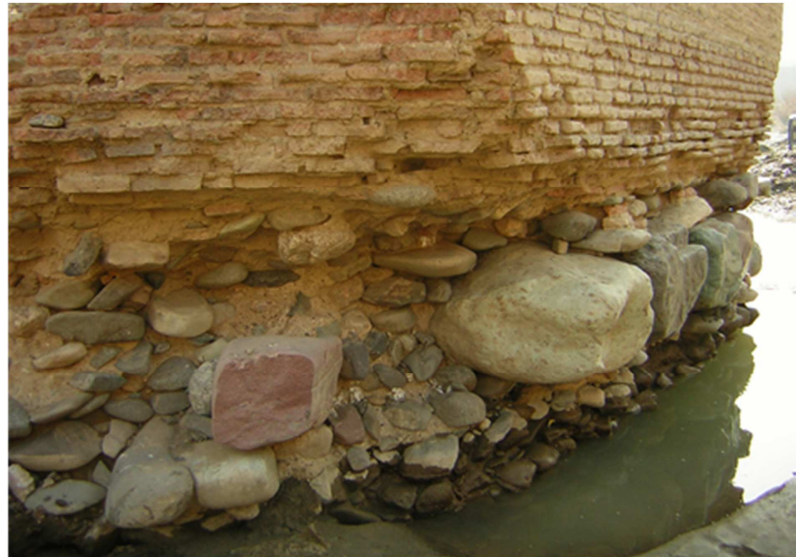

Figure 23. Foundation of the medial vault, before restoration 2006.

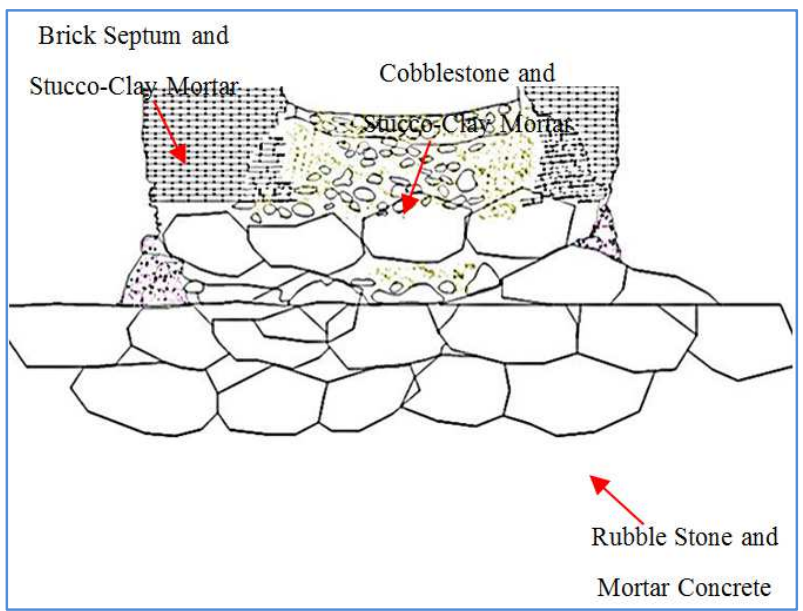

Figure 24. Details of the foundation, author.

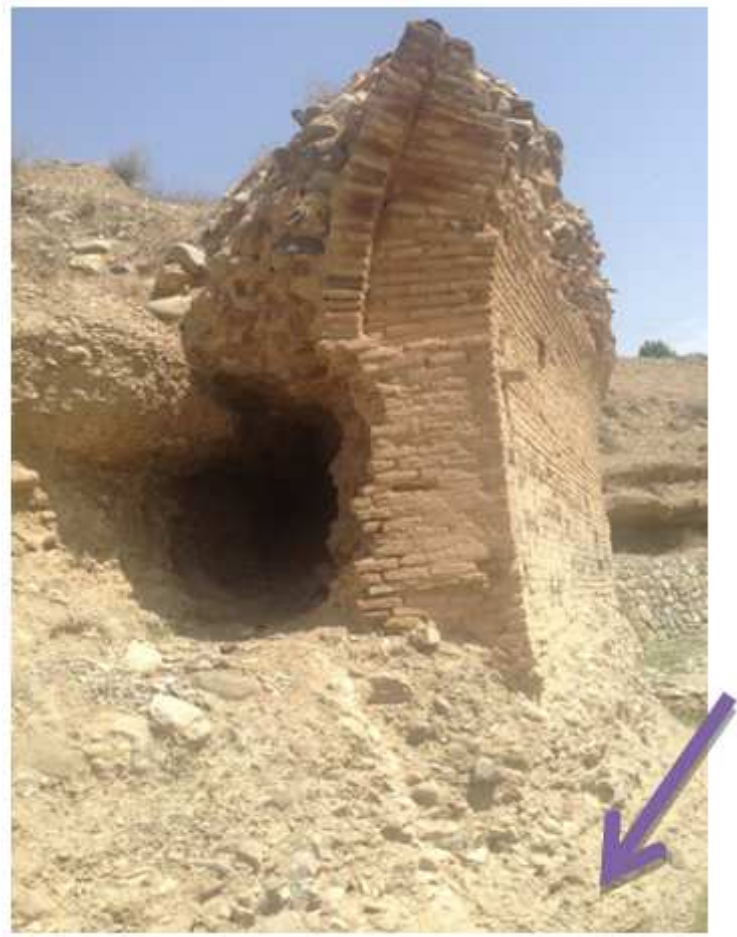

Figure 25. Western side and natural substrate composed of clay and calcareous salts. 
The man role of foundation is to transfer the load of the structure to the earth. Dimensions of foundation varies due to the type of the underneath land, loads of walls and the structure, and the building envelop. One of the most important issues in bridge construction is digging the foundation. The expected result from this phase is to provide a strong foundation for building piers on it (Ansari, 2013, 27). Based on what figures 22 and 23 shows, the foundation of the medial vault is constructed on rubble stone with Sarouj(Concrete) mortar on the toughest point of the riverbed. On the west side, foundation is built by the natural substrate (clay and calcareous salts).

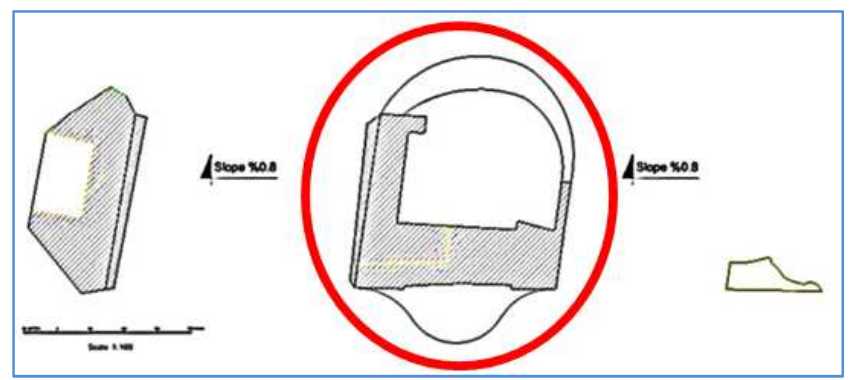

Map 2. Position of foundation (figure 24) on the plan.

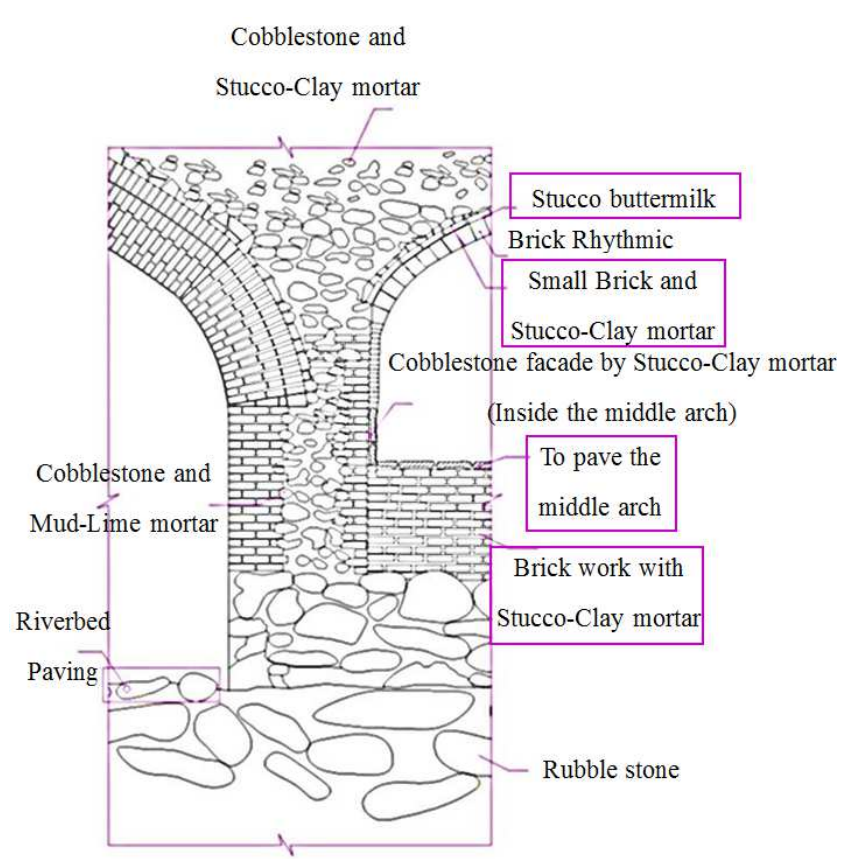

Figure 26. Details of sections of the bridge with materials and mortars.

\subsection{Considering Hydraulic of the Bridge}

As mentioned before, at the narrowest point of the river before water flow reaches spans, the river flow arrives to a curve by which the velocity, force and pressure of water is reduced. The constructers have selected the best point for constructing the bridge. A river with roughly $48 \mathrm{~km}$ length and an average slope of $08 \%$ (Geographical Organization, 2004).

The structure of foundations and historical bridges indicates that their designs are based on constructional and structural solutions and they mainly focus on resistance against water pressure. Obviously, bridges should be significantly heavy in order to ensure resistance and stability against water pressure. However, from hydrostatic and hydrodynamic point of view, weight of the bridge is not enough and in fact two more factors should be considered: the level of connection point of bridge to the riverbed, and the shape of the pillar (Heydari Bani, 1999, 424).

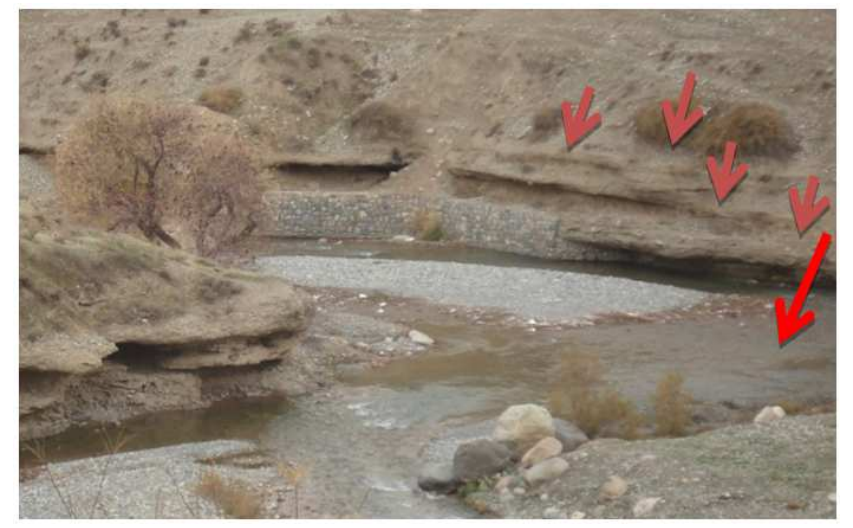

Figure 27. A landscape of the detour river and the surrounding walls, 2013, author.

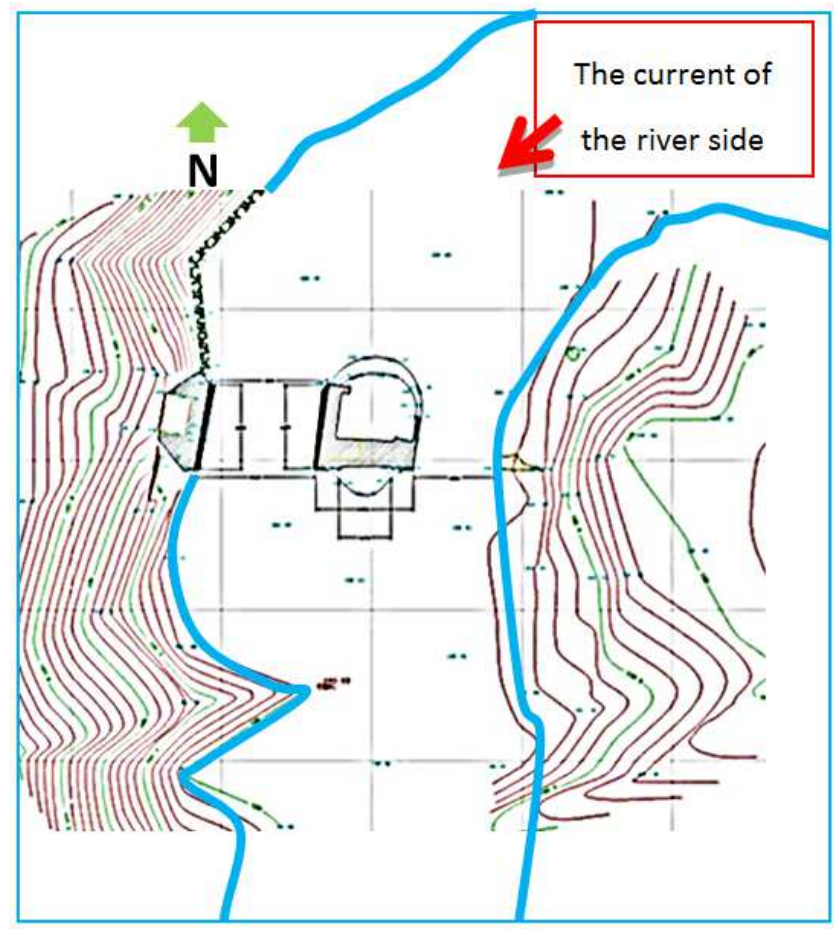

Map 3. Site plan of the river.

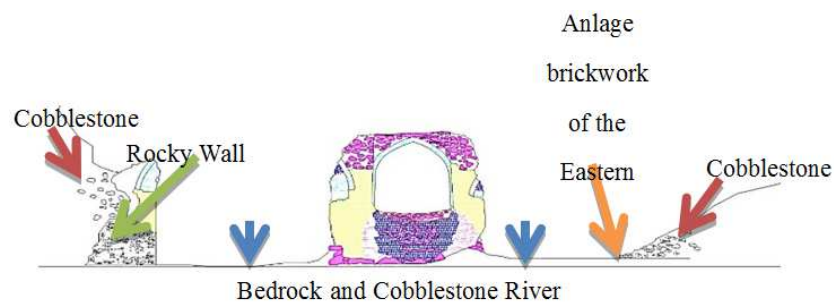

Figure 28. Connection level of Banu Sahra Bridge to the riverbed. 


\subsubsection{Shape of the Pillar and Hydraulic Effect of Water}

Bsorbing forces. Generally, shape of pillars is designed to act as a breakwater (except for a few cases they are not like a breakwater). The form of the breakwater reduces the dynamic force to the bridge. Therefore, weight, shape, and level of connection are integrated to neutralize the hydrostatic and hydrodynamic pressures of water. Each of acute or curved breakwaters- in the upstream side of the bridge- makes a surface in which the water flow becomes slow and is divided and conducted towards waterways of the bridge. The above mentioned breakwaters reduce the connection area between water the pillars and therefore the dynamic pressure of water is decreased. In the points where the water flow is vigorous, breakwaters are acute and where there is laminar flow of water, breakwaters are curved and round. But breakwater of this bridge is a rare type. They are round in both sides. This means that in the upstream side (northern side), shape of foundation and pillar is simple curved (semicircular) and in the downstream (southern side) they are slightly curved outward. Since the best form of breakwater is to make curves in both sides, the curve and the circle that is constructed in one side fits, howbeit it is defaced somehow, but causing deviation and making extra curve in the other side, has led to some damages to the body. This may also cause making cavities in the case of occurring fast and vigorous flow of water or floods.

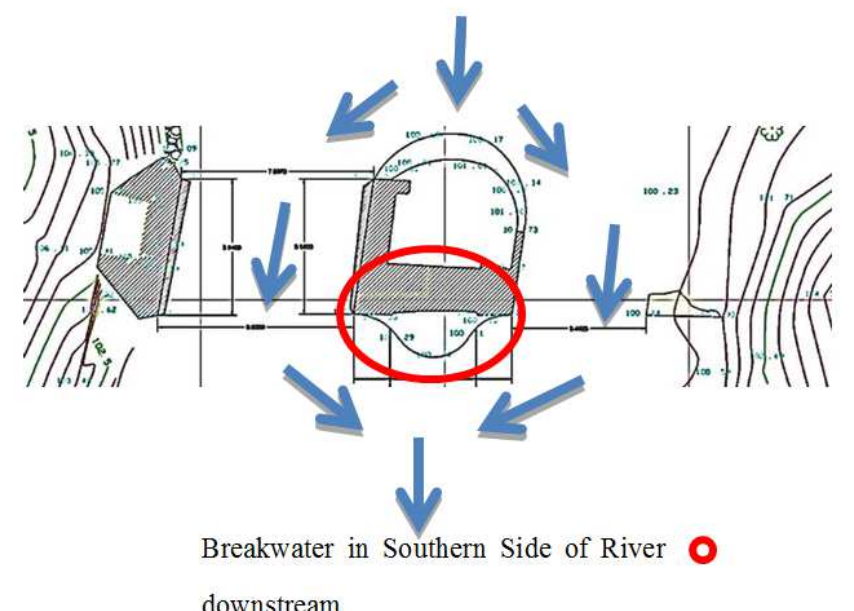

The flowing of water

Map 4. Plan of breakwater.

\subsubsection{Hydraulic Jump and Function of Riverbed}

Hydraulic jump: flow regime of water under the bridge is changed based on shrinking the profile, and therefore velocity increases (critical or supercritical flow). After passing the bridge, again it is converted into subcritical flow and therefore velocity is decreased (the flow regime is changed to subcritical if the profile becomes greater after the bridge and the slope is converted to the natural slope of the river).After the bridge, converting the flow regime of water from super critical into subcritical leads to hydraulic jump. In this phenomenon, velocity of water flow is decreased but the depth of flow is increased. As a result of hydraulic jump energy is released which in turn, it leads to erosion and leaching of the riverbed.

One of the protective measures against the threat of erosion and washout is creating flagstone of the river bed in both sides of the bridge. This means that the riverbed is paved by rubble stone in both upstream and downstream of the bridge. The above mentioned pavement of flagstone is expanded 10 to 20 meters from both sides. The flagstone of the riverbed usually consists of smooth cobblestones or slates. This flagstone provides a foundation which possesses a special degree of protection and protects the bridge against hydraulic issues and problems which cause erosion of the river.

The flagstone transports the location of the scouring to a point farther in the upstream of the bridge. Hence, scouring does not occur close to pillars and foundations. On the other hand, in the downstream of the bridge, the flagstone changes the location of hydraulic jump to a father point in the downstream. The jump occurs at the end of the downstream where slope of the substrate is the natural slope of the river. Therefore, the resulted erosion and scouring from hydraulic jump recedes from pillars and foundation, and will not be disembogued in downstream. In general, the flagstone of the floor of waterways of the bridge, shape of pillars and the flagstone in both sides of the bridge remove all negative impacts of water flow on pillars and foundations. Inclining to the floor of waterways and flagstone in the downstream in addition to the fact that water suddenly enters a greater area with a higher slope in comparison with the natural slope of the river after exiting from waterways, leads to more velocity of water. In this case, when flooding occurs water is evacuated faster from the bridge. In the normal and non-flooding mode, after waterways, water flows as a tenuous and lucid layer due to the slope of the riverbed and type of regime of flow (critical or super critical). After hydraulic jump occurs, velocity of water flow is decreased while the depth of water is increased and water flows slowly with a subcritical regime. As a result, level of the river seems pacific like a lake. At the point of hydraulic jump (at the end of flagstone of downstream) a natural pacific laver is created which its hydraulic status is in equilibrium with the released energy from the water mass.

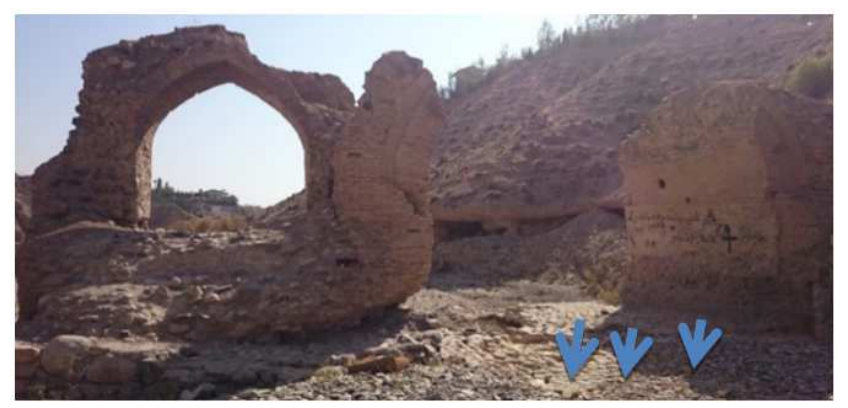

Figure 29. The river bed (substrate) summer of 2014.

\section{Discussion and Conclusion}

It is important to restore, and furbish this monument due to various researches and studies about the history, architecture 
and structure of Banu Sahra Bridge, especially while it is confirmed that it dates back to Safavid era (which was repaired in Qajarid era). To achieve this, other phases of the restoration process such as pathology must occur and at the end the comprehensive plan of its restoration is presented. It is remarkable to note that the mentioned plan was presented in February of 2015 by the author.

\section{References}

[1] Ansari, Ali Mohammad, 2013, study and restoration plan of trap Kall of Kharanegh from strengthening point of view, Master of Art dissertation, Islamic Azad University, Yazd branch.

[2] Asar Magazine, Vol. 24, arches and vaults, reprint in 2011.

[3] Cleis, wolfram, Iran Islamic architecture, translated bt Alireza Mahini, collected by Mohammad Yousef Kiani, 2000, Tehran, SAMT Publication.

[4] Fayazi Maral, 2014, restoration plan of Banu Sahra Bridge in Savojbolagh from technological approach to its mortars, Master of Art dissertation, Islamic Azad University, Yazd branch.
[5] Gollabchi, Mahmoud; Javani Dizji, Aidin, 2013, Technology of Iranian Architecture.

[6] Ghobadian, Vahid, 2008, a climatic study on traditional constructions in Iran.

[7] Hamedi, Ahmad, 1994, water assess and water supply, Building and Housing Research Center, Journal of Tehran University, Vol. 2.

[8] Heydari Dariush Bani, 1999, hydrological study about historical bridges Cultural Heritage Organization, $2^{\text {nd }}$ Bam congress, third Vol.

[9] Historical studies Archive of Savojbolagh gubernatorial, 2003.

[10] Kiani, Mohammad Yousef, 2006, Islamic Artitechture, Tehran.

[11] Mohebali, Mohammad Hassan; Mohammad Moradi, Asghar; and Eng. Atashsa Amir Kabirian, 1995, 12 lessons about restorations, Ministry of Housing and Urban Development, National Land and Housing Organization.

[12] Noori, Babak, Restoration plan of Karaj Shah Abbasi bridge, 2009, Bachelor's degree dissertation of Islamic Azad University, Hamedan branch.

[13] Zanjani, Zekrollah, 2006, Historical Identity of Savojbolagh, gubernatorial of Savojbolagh, Avaye noore Tehran Publication. 